\title{
O IMPERATIVO DO ENVELHECIMENTO ATIVO E AS TECNOCIÊNCIAS: IMPLICAÇÕES SOBRE A SEXUALIDADE DO IDOSO
}

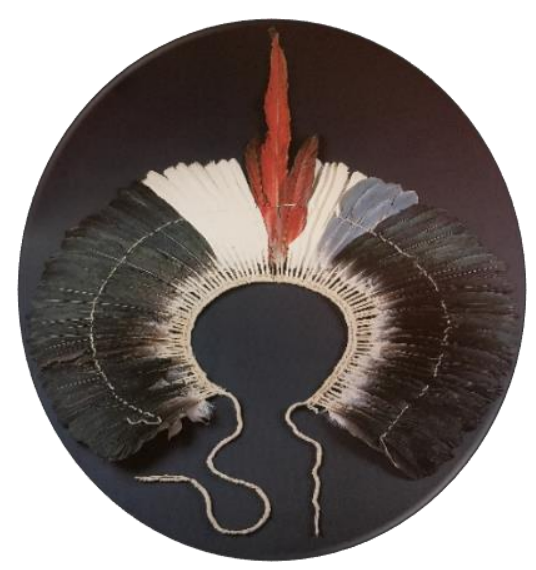

Alice Alves Menezes Ponce de Leão Nonato ${ }^{1}$

Yoshiko Sassaki

RESUMO: O imperativo do envelhecimento ativo é apropriado pelas tecnociências em uma lógica associada ao ideário neoliberal fundamentada no consumo, na beleza e na produtividade. Em busca pela qualidade de vida na "terceira idade", os idosos são envolvidos em uma atmosfera que propaga o autocuidado, a independência e a autonomia, na meta de "morrer jovem o mais tarde possível". Para a realização deste trabalho, recorreu-se à pesquisa bibliográfica sobre velhice, sexualidade e saúde, promovendo a interlocução com as tecnociências, a partir de uma perspectiva interdisciplinar. Concluise desse estudo que sob a influência midiática, a sexualidade do idoso é posta à prova, pois, se por um lado, é necessário reconhecer que as mudanças fisiológicas e psíquicas redimensionam o sentido da atividade sexual na velhice, por outro lado, a maioria dos idosos ainda empobrece o sentido

\footnotetext{
${ }^{1}$ Assistente Social; Doutoranda no Programa de Pós-Graduação em Sociedade e Cultura na Amazônia, da Universidade Federal do Amazonas (PPGSCA-IFCSUFAM)

2 Professora do Departamento de Serviço Social e do Programa de PósGraduação em Sociedade e Cultura na Amazônia, da Universidade Federal do Amazonas (UFAM)
} 
dessa atividade ao reduzi-la ao coito, imbuídos de um imaginário midiático socialmente construído que cultua a imortalidade do corpo e o seu rejuvenescimento como forma de sentir-se vivo nas sociedades contemporâneas.

PALAVRAS-CHAVE: Envelhecimento. Tecnociências. Saúde. Sexualidade. Corpo.

\section{INTRODUÇÃO}

A produção literária sobre o envelhecimento e a velhice tem ganhado notoriedade nas últimas décadas não só pela visualidade do número de idosos no universo populacional brasileiro, mas pelo despertar da ciência e de profissionais em razão da preocupação com o aumento das demandas desse estrato populacional pelos serviços de saúde, previdência e assistência social, causando ônus para o Estado (TEIXEIRA, 2008) e demandando um conjunto de estratégias que proporcionem melhores condições de vida futura para os homens do presente.

Em termos demográficos, a Pesquisa Nacional por Amostras de Domicílios (PNAD, 2012), divulgada pelo Instituto Brasileiro de Geografia e Estatística (IBGE) apontou a existência de 24,85 milhões de indivíduos com 60 anos ou mais, representando 12,6\% da população brasileira. As projeções acusam que até 2025 , o Brasil poderá ocupar o $6^{\circ}$ lugar no ranking mundial em relação ao número de velhos.

O aumento da longevidade da população pode ser explicado graças aos avanços da ciência, sobretudo no campo da medicina, no que concerne ao controle de doenças infectocontagiosas, reduzindo, então, os índices de mortalidade, e também devido à redução nas taxas de fecundidade, em razão dos métodos contraceptivos e pelo ingresso da mulher no mercado de trabalho (LITVOC e BRITO, 2004).

Se, por um lado o envelhecimento é celebrado, por outro, é visto como uma espécie de "neurose nas sociedades modernas" (MERCADANTE, 2003), tendo em vista que nos moldes do capitalismo 
ocidental a produtividade e o culto à eterna juventude repelem a imagem do idoso, geralmente associada a um corpo doente, onde sobressai a representação da pobreza, decrepitude e morte.

"O persecutório e apavorante temor do que acontecerá diante do fenômeno do envelhecimento demográfico passa a ser uma preocupação central no âmbito da ciência, da política e da economia" (CERQUEIRA, 2012)> Esse argumento tem orientado a redefinição de políticas e programas voltados aos idosos e impulsionado o reconhecimento da geriatria e da gerontologia como profissões do futuro, conforme publicado na Revista Isto É em 2010, despertando interesse de estudiosos e profissionais de diferentes campos do saber, em busca pela qualidade de vida na "terceira idade".

A meta da gerontologia: "Morrer jovem o mais tarde possível", postulada por Schubert (1977), tem colocado em evidência a saúde como forma de se obter modos de vida mais saudáveis na velhice. A própria concepção ampliada de saúde estabelecida pela Organização Mundial da Saúde (OMS) como o completo estado de bem-estar físico, social, psicológico, econômico, cultural e espiritual desdobra-se sobre o propalado envelhecimento ativo e/ou bem-sucedido, através da valorização de aspectos como o autocuidado, independência, autonomia, participação, dignidade, autorrealização, por meio da participação dos idosos em atividades físicas e de lazer, de geração de renda, em programas de controle de saúde, dentre outros.

Apesar dos méritos que as novas tecnologias têm propiciado às biociências, às ciências do espírito e às ciências da sociedade, o poder das tecnociências se torna preocupante pela perseguição desenfreada à perfectibilidade, com ressonâncias no campo da cultura e dos valores contemporâneos. No que tange ao envelhecimento, as tecnociências tem promulgado um debate no campo da intergeracionalidade (na perspectiva da formação de um novo senso comum) ou fomentado um biopoder narcisista, centrado no culto ao corpo e na sua imortalidade? 
Sendo a sexualidade na velhice uma atividade reconhecida por gerontólogos e sexólogos como benéfica para o envelhecimento ativo/bemsucedido, a polarização do debate problematiza a caracterização do corpo do idoso, o prazer sexual nessa fase da vida e a forma como a mídia e a indústria farmacêutica ora promulga o mito da velhice assexuada, ora reverencia a erotização, onde as disfunções sexuais podem ser tratáveis (destaca-se a introdução do Viagra), acentuando a penetração e criando uma tensão no universo de concepções de homens e mulheres idosos acerca de sua sexualidade.

As tecnociências, assumidas pelo ideário neoliberal, fundamentamse na prioridade do consumo em detrimento às prioridades sociais (YANARICO, 2011). Assim, as biotecnologias, à medida que se preocupam em "corrigir" as marcas do tempo, transferem para os indivíduos a autorresponsabilidade pelo prolongamento de suas vidas sob um discurso midiático de reinserção dos idosos nos espaços sociais e produtivos, e isso demanda a "prática de exercícios físicos, monitoramento médico e tratamentos cosméticos e cirúrgicos capazes de restituir a longevidade" (CERQUEIRA, 2012, p. 28).

Como pensar, então, a sexualidade do idoso, enquanto dimensão do viver, em um país hedonista, promotor do culto da beleza, da juventude e da sexualidade restrita à genitalidade? A proposta deste artigo consiste em problematizar as tecnologias de intervenção sobre a velhice (tecnociências) e a influência midiática que, na realidade, perpetua a ideologia do consumo e mascara a desresponsabilização do poder público frente à complexidade que se trata o fenômeno do envelhecimento.

\section{QUALIDADE DE VIDA NA “TERCEIRA IDADE” SOB O AUSPÍCIO DAS TECNOCIÊNCIAS}

O conceito de envelhecimento é envolvido em uma polissemia que o torna complexo, pois apesar de ser condição humana, natural e inevitável, é marcado por mudanças biológicas, fisiológicas, psicológicas, sociais, 
econômicas e políticas (NERI, 2001), que diferenciam as variadas formas de envelhecer pelos indivíduos, segundo fatores como a saúde física e mental, a família, o gênero e a classe social (BEAUVOIR, 1990).

As terminologias utilizadas pelas pessoas que atingem o estágio do envelhecimento também são diferenciadas, levando em consideração, sobretudo, a classe social. Segundo Peixoto (1998), na França do século XIX, o termo vieux (velho) ou vieillard (velhote) era utilizado para as pessoas com idade acima de 60 anos, consideradas como pobres e indigentes, pois não tinham condições financeiras para assegurar seu futuro.

Por outro lado, os indivíduos que gozavam de prestígio social, eram chamados personne âgée (idosos). A partir dos anos 1960, o termo "idoso" chega ao Brasil trazido pelos ventos franceses. Velho e idoso podem confundir-se, mas "idoso" marca um tratamento mais respeitoso, como personne âgée praticado na França, enquanto o termo "velho" tem uma conotação negativa ao designar, sobretudo, as pessoas de mais idade pertencentes às camadas populares que apresentam mais nitidamente os traços do envelhecimento e do declínio.

"Terceira idade", segundo Mercadante (2003), é sinônimo de envelhecimento ativo e independente, uma nova etapa da vida em que a ociosidade (em razão da aposentadoria) simboliza a prática de novas atividades sob o signo do dinamismo. Esse termo surge na tentativa de desconstruir a categoria "velhice" e a identidade estigmatizada que permeia a palavra "velho" (descartável, feio, doente etc.). Designa, principalmente, os jovens velhos, os aposentados dinâmicos.

No início do século XXI, as proposições em torno da velhice caminham rumo à construção de novos projetos de vida, o que exige primeiramente que as pessoas gozem de um bom estado físico de saúde. Um conceito que vem ganhando expressão é o do "envelhecimento ativo", que designa o envelhecimento como uma experiência positiva. 
Segundo Albuquerque (2008), o "envelhecimento ativo" é definido pela Organização das Nações Unidas (ONU) como um processo de otimização de oportunidades de bem-estar físico, mental e social através do curso da vida, de forma a aumentar a expectativa de vida saudável e a qualidade de vida na velhice. Apesar de ser um termo difícil de ser precisado, "qualidade de vida" pode representar "uma vida longa com um melhor estado de saúde, condições distribuidas equitativamente entre os indivíduos e os grupos que formam a comunidade" (p. 83).

Quando não submetido a uma análise crítica, o imperativo do "envelhecimento ativo" nos remete a um contrassenso que atropela a ética, pois, se por um lado, reconhece-se que na velhice há um estreitamento das possibilidades de escolha, em razão dos modelos sociais naturalizados e pelo declínio da capacidade funcional, por outro lado, existe uma pressão social e psicológica (que gera insatisfação) sofrida pelo "não enquadramento" no paradigma do “idoso saudável” (FENSTERSEIFER, 2009).

Esta idealização, esta promoção de estereótipos da "boa velhice" (que brinca, que corre, que trabalha) empobrece nossa percepção desta etapa da vida, pois não nos permite enxergar diferentes "possibilidades de viver", mas enfatiza "deficiências a corrigir". Esta é a base do discurso eugenista que promove a intolerância e a coisificação, tornando-nos incapazes de suportar a diferença e a individualidade, uma vez que esta promove aquela (op. cit., p. 86).

Para Bruno (2006), inaugura-se a era do biopoder, "cuja força e suporte não são nem a religião, nem o Estado e suas instituições, mas as biotecnologias e sua presença nos meios de comunicação" (p. 72). O direito à saúde ultrapassa o tratamento e a cura, o que entra em campo, na atualidade, é a manutenção do bem-estar pelo período mais longo possível. Essa mudança implica em novas práticas, regimes e princípios de cuidados de si, onde não basta mais a ausência de doença para que um indivíduo seja considerado saudável, mas uma séria vigilância das predisposições genéticas e o controle de fatores de 
riscos para evitar o que pode vir a ser (grifo próprio), assim, "é em torno do possivel que se dá a gestão do corpo" (p. 69).

Nesse processo, a mídia tem fator decisivo, pois informa as doenças que os indivíduos podem vir a ter, caso se alimentem de maneira inadequada ou no sentido de necessidade de uma atenção redobrada sobre a própria saúde se houver um parente próximo que possa ter um gene predisposto a uma doença crônica, como hipertensão, diabetes, câncer etc. Segundo a autora:

Os meios de comunicação nos oferecem cotidianamente imagens do nosso corpo, genoma, cérebro, nossa sexualidade, nossas patologias físicas e mentais. A genética e a epidemiologia são os temas privilegiados; as páginas de jornais e revistas, bem como programas televisivos, estão povoadas de preceitos de saúde e novos genes. Alguns exemplos: "Estudos indicam alimentos contra infarto e derrame"; "O estresse contínuo, que quebra a 'harmonia silenciosa' do organismo, leva cada vez mais cariocas aos consultórios médico..."; "Vida sedentária aumenta risco de osteoporose"; "Genes podem explicar origem da esquizofrenia"; "Obesidade pode ter origem genética"; "Genes podem decifrar mal de Alzheimer"; "Saiba tudo sobre o suposto gene da homossexualidade"; "A saúde como herança” (BRUNO, 2006, p. 66).

A tecnociência sustentada no biopoder da medicina, aliada aos meios de comunicação, legitima um campo de regras, preceitos e poderes ao disseminar uma tensão de temor e controle, envelhecimento e morte, recaindo sobre os indivíduos a responsabilidade de evitar ou adiar os males que podem vir a se tornar realidade. Depreende-se, então, que o indivíduo é capaz de programar o prolongamento de sua própria vida e as consequências de se tornar um idoso saudável ou doente.

A forma das tecnociências sobre a vida tem recaído no ideal de jovem e saudável, seja através do gerenciamento de riscos de adoecer e morrer quanto também no sentido de remodelar imperfeições, através das cirurgias plásticas, no intuito de que, na velhice, o sujeito possa voltar a ser 
ágil e produtivo para que, assim, seja possível dar continuidade a permanência/inclusão nos espaços sociais e produtivos, a atividade sexual etc.

O discurso da qualidade de vida e da vida saudável que atualmente legitimam o corpo nos diferentes grupos de idade, exige graus de performance de cada indivíduo, a partir de escolhas e comportamentos adequados e corretos. No caso da velhice, a exigência parece mais complexa, uma vez que as condutas saudáveis têm implícita uma "volta ao passado", segundo a qual se deve atingir patamares de rejuvenescimento que favoreçam a aceitação e reinserção social, mantendo-se compromissos duradouros com o próprio corpo. É através de um ideal (jovem) de envelhecimento que o sujeito volta a ser ágil e produtivo que se abrem novos espaços sociais (CERQUEIRA, 2012, p. 36).

Mas, o que vem a ser as tecnociências? Segundo a definição de Yanarico (2011), a partir de Bruno Latour, tecnociência é um recurso de linguagem para denotar a íntima ligação entre ciência e tecnologia. Constituise como uma das formas de saber que tem se tornado de fundamental importância para a decisão dos estilos de vida, educação e cultura, a partir de uma concepção de mundo fundamentada e de um sistema social de mundo determinado, que dita formas de desenvolvimento e subdesenvolvimento das sociedades. Assim,

A racionalização tecnocientífica de controle da natureza de tradição moderna estende-se ao controle do próprio homem. A ciência e a tecnologia da sociedade capitalista contemporânea fundamentam-se num conjunto de valores institucionais para ações, tais como: a eficácia, o progresso, o desenvolvimento, liberdade de consumo, especialmente nos valores da neutralidade $\mathrm{e}$ determinismo científico tecnológico. A tecnociência neoliberal integra-se à lógica capitalista para maximizar os ganhos a menor custo, tornando-se, simplesmente, numa força de produção sem prioridades sociais. Acumulando renda em alguns indivíduos sem pátria (os, aparentemente, globalizados) e mantendo miseráveis, 
tais como a grande maioria da população (YANARICO, 2011, p. 99).

As tecnologias de intervenção sobre a velhice recaem, sobretudo, sobre os avanços da biomedicina, no sentido de reprogramar o corpo e o comportamento dos indivíduos na contemporaneidade. As mudanças biológicas e psicológicas que perpassam o processo de envelhecimento são apropriadas pelo saber médico, no intuito de "combater" os "efeitos negativos" que têm no corpo a sua maior expressão. Aparecem, assim, os complexos vitamínicos, os suplementos alimentares, cremes de rejuvenescimento, cirurgias plásticas, dentre outros itens na esfera do consumo, glamourizados no ideal de um corpo jovem, bonito e saudável, que conduz à felicidade.

\section{A SEXUALIDADE NA VELHICE E O DISCURSO DOS CORPOS MIDIÁTICOS}

Netto e Ribeiro (2005) observam que a sexualidade na velhice é um dos temas mais abordados em grupos de convivência de idosos e que desperta maior interesse desse público-alvo. Primeiro, porque a vida sexual deixou de ter apenas a função de procriação para se tornar uma fonte de satisfação e realização de pessoas de todas as idades; segundo, pelo notável aumento de pessoas que chegam a uma idade avançada em condições psicofísicas satisfatórias e que não estão dispostas a renunciar à vida sexual, e terceiro, pelo aumento de idosos infectados pela Síndrome da Imunodeficiência Adquirida (AIDS), o que reforça a necessidade de se falar mais abertamente sobre sexo.

Se falar sobre sexualidade ainda se constitui um tabu, carregado, sobretudo de repressões ético-religiosas e culturais, relacioná-la ao universo da velhice chega a ser considerado, muitas vezes, como ofensivo e imoral. Isso porque o modelo de sexualidade estabelecido como "normal" é centrado no culto ao corpo, à juventude, à beleza, na consideração do sexo como fonte de prazer centrado no coito e para fins de procriação. 
E como beleza e juventude são fatores que declinam com o tempo, além de aspectos relacionados a distúrbios hormonais, fatores emocionais, culturais e distorções religiosas que consideram o sexo nessa fase da vida como algo sujo e pecaminoso, tem-se no imaginário social que o idoso é assexuado, onde dele se espera, no máximo, que seja um (a) bom (a) avô ou avó para cuidar dos netos, privando-o de um direito fundamental que faz parte de sua condição humana, que é a sexualidade. "Muitas vezes é o ambiente e a falta de oportunidade que desestimulam o idoso ao sexo" (RIBEIRO, 2005, p. 125).

Cumpre destacar que sexualidade pode ser entendida como:

A maneira como uma pessoa expressa seu sexo. É como uma mulher vivencia e expressa o ser mulher e o homem o ser homem. Expressa-se através dos gestos, da postura, da fala, do andar, da voz, das roupas, dos enfeites, do perfume, enfim, de cada detalhe do indivíduo. Confunde-se muito sexualidade com relação sexual. A relação sexual é um componente da sexualidade ao contrário do que muita gente pensa não é apenas a relação pênis-vagina, mas sim, a troca de sons, cheiros, olhares, toques, secreções e carícias (NETTO e RIBEIRO, 2005, p. 124).

Assim, privar o idoso do exercício de sua sexualidade é como negar a próprio sentido de existência, do direito de sentir-se vivo. "O seu impedimento é como se vivificassem a mortificação do desejo sexual, do embelezar-se para seduzir, do romantismo, do encantamento e da possibilidade de ser reconbecido pelo outro" (UBESSI et al, 2009, p. 275).

Para Pascual (2002), ainda que exista um certo confusionismo na definição da sexualidade longeva, até porque "para alguns, a sexualidade é tão ampla que abarca e se expande por todos os componentes e aspectos da pessoa sexuada, e para outros, é tão pobre que a reduzem à função genital reprodutora ou a meros atos sexuais" (p. 28), a sexualidade do idoso exige ser compreendida em uma visão integral, se acreditamos que ela não finda com o decurso dos anos e nem se limita à função genital ou ao ato sexual. Na velhice, a sexualidade não sofre 
degeneração, apenas muda qualitativa e quantitativamente suas formas de expressão.

A sexualidade como um todo sexuado que somos, pelo qual nos expressamos, permite-nos ver diferentes possibilidades de comunicação, afeto, prazer, mediante manifestações diversas, contanto que sejam aceitas livre e reciprocamente, permitindo aos idosos reconhecerem seu direito de vivê-la e desfrutar suas possibilidades de prazer, afeto, encontro, relação, comunicação etc. (2002, p. 28).

O autor observa que a aceitação ou a rejeição da vida sexual dos idosos estão condicionadas por fatores sociais e não exclusivamente biológicos. Ou seja, as alterações fisiológicas que ocorrem no corpo do homem e da mulher velhos não são tanto significantes quanto o peso cultural de uma sociedade que os excluem e os discriminam. A desvalorização do idoso na sociedade trouxe junto sua desvalorização sexual.

Para compreender o comportamento sexual do idoso, é imprescindível conhecer os papéis, funções, costumes sexuais da sociedade. As dificuldades sexuais, hoje, dos idosos não são devidas a um fato isolado, mas a esta sociedade que os rodeia e tem suas raízes fundadas no passado. [...] Os idosos tendem a adotar os estereótipos que a sociedade onde nascem e vivem reservou para eles no campo sexual. A opinião pesa e o sujeito dobra-se mansamente ao ideal de convivência, para não se sentir ainda mais marginalizado e condenado como velho "sem-vergonha" ou "pervertido". Os papéis sociais oferecem-lhes nesta idade uma imagem dessexuada e idílica, enfocada no cuidado dos netos e na negação das paixões sexuais, realidade esta vedada para eles (2002, p. 42).

O trato dispensado ao idoso na sociedade capitalista é revestido de caráter estigmatizador. Associa-se comumente a velhice à feiúra, à doença, tristeza, pobreza, decrepitude e morte. Isso porque a cultura que permeia a sociedade moderna é aquela centrada nos moldes de produção capitalista, 
onde "toma o jovem e o adulto como produtores e considera o velho como uma irrupção perigosa da ordem, posto que já não é mais produtivo para o capital' (GUSMÃO, 2003, p. 157).

Em um modelo de sociedade que valoriza a juventude e a beleza, observa Almeida (2003), o horror à velhice justifica-se em razão de uma cultura centrada no culto do eu. Trata-se de uma personalidade narcisista, onde o indivíduo precisa ser admirado por sua beleza, encanto, celebridade ou poder, atributos que geralmente declinam com o tempo.

O corpo do idoso remete a um conjunto de representações através das quais sobressai a imagem da doença. A doença é um estado de impureza que representa um perigo porque é capaz de poluir e contagiar os outros. Por isso, evita-se a presença dos idosos, evita-se tocá-los, evita-se amá-los, porque o velho representa a própria condição humana futura para os homens do presente. O medo da velhice e das doenças constitui uma espécie de neurose nas sociedades modernas (ROCHA, 1998).

Apesar do mito da velhice assexuada, nas últimas décadas ascende um debate promotor da erotização na velhice. Gerontólogos e sexólogos tem se empenhado em defesa de uma sexualidade nessa fase da vida que seja realista às mudanças fisiológicas e psíquicas que levam à diminuição ou até mesmo ao desinteresse dos idosos pela atividade sexual, fundamentando-se em uma perspectiva de sexualidade muito mais ampla do que o ato de copular, estimulando outras possibilidades centradas na comunhão, no toque, no carinho etc.

Entretanto, Debert e Brigeiro (2012) explicam que o triunfo dessa perspectiva não encontra expressão absoluta, principalmente no momento em que se introduz a discussão da sexualidade na velhice no espectro da categoria "Terceira Idade", construída como símbolo do envelhecimento ativo, onde

Uma nova linguagem pública empenhada em alocar o tempo dos aposentados faz-se presente na 
desconstrução das idades cronológicas como marcadores pertinentes de comportamentos e estilos de vida. Uma parafernália de receitas envolvendo técnicas de manutenção corporal, comidas saudáveis, medicamentos, bailes e outras formas de lazer é proposta, desestabilizando expectativas e imagens tradicionais associadas a homens e mulheres em estágios mais avançados da vida. É no marco dessas transformações que podemos localizar o processo vigente de erotização da velhice (2012, p. 39).

Uma velhice sexualmente ativa vem se estabelecendo como um ideal propagado intensamente pelos meios de comunicação de massa. As tecnociências, através da indústria farmacêutica e da biomedicina, tem se encarregado de "corrigir" os problemas sexuais enfrentados por homens e mulheres na velhice através das tecnologias medicamentosas (o Viagra, por exemplo) e cirurgias plásticas (para o prolongamento do corpo jovem).

Para Gonçalves (2011), pensar o corpo na contemporaneidade impõe aos indivíduos a preocupação com o que seja a salvação e a morte. $\mathrm{O}$ modo de tratar o corpo é auxiliado pelas tecnologias biomédicas, informacionais e genéticas, respaldado em discurso científico propagado pela mídia que impõe aos indivíduos um modo de saber/fazer como condição de ser e viver no planeta. Transmite-se a ideia de um desconforto existencial com a própria biologia que deve ser resolvido com o auxílio das tecnociências, sobretudo as biotecnologias.

Vivemos a época de efervescência das "tecnologias da vida". A morte parece deixar de ser uma condição da vida, tornando-se uma fronteira relativa ao avanço potencialmente infinito da tecnobiologia. As possibilidades trazidas pelas novas tecnologias da informação (incluindo aí as biotecnolologias, nanotecnologias, engenharia genética) apontam para a possibilidade e a probabilidade de uma imortalidade em vida (a-mortalidade). Ansia-se e quer-se a "vida eterna" - mesmo que essa, no momento, seja apenas o alargamento do prazo da permanência em vida - em carne, sangue e músculos. (2011, p. 01). 
A promessa do "expandir humano" é o que a autora chama de virtualização dos corpos, mediatizados pelas tecnociências e pela mídia. $\mathrm{O}$ virtual não significa o que não é real. Ao contrário, é como um real que ainda não se atualizou, mas que se constitui como uma potência em vias de realização.

Ao explicitar através de um exemplo, compara como se fosse um "espelho de bruxa", onde todos os dias "o narciso contemporâneo que desperta em nós a cada manhä’ (GONÇALVES, 2011, p. 04), no lugar de uma bela imagem refletiva, devolve sempre uma falta, uma necessidade de reposicionamento, proveniente do nosso "eu” biológico ou do nosso psiquismo. O imperativo é a saúde perfeita, que se expressa no controle das doenças e na aparência de um corpo jovem e saudável.

Nesse processo, a mídia age como um ímã sobre o imaginário social dos indivíduos. Assim,

A produção, ou adaptação constante e orbital a novos modelos físicos (agenciando sempre "a última novidade", a última "descoberta" da Ciência) não deixam outra opção ao indivíduo que não a "troca de pele" incessante, num redimensionamento sem fim de seu corpo. A atualização assim é permanente, e o corpo passa a ser um laboratório (um campo de ensaios, de tentativas e erros) em retro-alimentação constante, ou seja, a cada novo modelo, novas combinações são feitas. A corporeidade assim concebida transforma-se em estratégia, na qual a realidade e o imaginário se perpassam, bem como o corpo e a técnica, produzindo um ser mutante, para alguns pós-humano - destino do homem contemporâneo (GONÇALVES, 2011, p. 04).

Em consonância aos interesses do capital, o alto custo dos mecanismos de imortalidade faz com que não sejam acessíveis a todos os idosos. Mais do que isso, a sexualidade do idoso sob o discurso dos corpos midiáticos pode tolher o exercício dessa atividade, principalmente no caso das mulheres, onde o corpo parece a âncora da mulher no mundo, sua razão de ser para si mesma e para o outro. "A ideia da passagem do tempo e seus rastros, 
os cabelos grisalhos e as rugas visiveis no seu rosto remetem à representação do ser velha e a temida condição de mulher velha" (FERNANDES, 2009, p. 420).

Vemos com isso, muitas vezes, o descompasso no momento da busca pelo novo par. Segundo Pascual (2002), é mais comum que os homens voltem a se casar novamente e, desta vez, com mulheres mais jovens, enquanto as mulheres idosas esbarram em fortes preconceitos, caso procurem se relacionar com homens mais jovens.

Debert e Brigeiro (2012) endossam essa assertiva ao mostrarem que os homens idosos que demonstram ter interesse na atividade sexual em suas velhices, manifestam o imperativo da masculinidade ao se interessarem por mulheres mais jovens, com forte impulso de erotização sobre a genitalização da sexualidade.

Já as mulheres dizem que "ter vida sexual na velhice é um desejo dos 'velhos bobos' que não percebem que apenas o dinheiro pode atrair as mulberes jovens que eles conquistam" (p. 48). Elas expressam sua sexualidade através do "sentir-se viva", traduzido no embelezar-se, na inserção em atividades de socialização e, só em último caso, no desejo de encontrar um novo amor que possa vir a se tornar um companheiro.

Os autores observam que parecem que os idosos (reportando-se aos entrevistados em suas pesquisas) não estão interessados nos esforços da gerontologia e da sexologia em alargar as potencialidades da sexualidade humana, pois continuam relacionando a sexualidade à genitalização. Tal questão torna-se preocupante, pois as pessoas estão envelhecendo em um país que tem sido pensado como promotor do culto e da beleza, da juventude e da sexualidade reduzida ao coito.

Se a sexualidade na velhice é considerada como uma dimensão do viver, cumpre desconstruir os estereótipos que perpassam a complexidade da vida social que tem reduzido essa atividade a um ponto de vista unilateral. As tecnociências, redimensionadas contrariamente aos interesses do capital, podem contribuir possibilitando processos de inovação e desenvolvimento, 
onde uma multiplicidade de atores deve ter presença, no questionamento de valores sociais e em novas formas de aprendizagem social a partir das necessidades humanas dos idosos. 


\section{CONSIDERAÇÕES FINAIS}

A sexualidade do idoso deve ser estabelecida por uma nova linguagem que, conforme defende Capodieci (2000), é tanto física quanto emocional e comunicativa. A linguagem de uma sexualidade integral na velhice é mais rica porque não é instintiva e, sim, aprendida, estreitamente ligada à capacidade de reconhecer e compartilhar os próprios sentimentos, o que possibilita a criação de possibilidades e experiências afetivas inovadoras.

Os estudos apontam que a cessação da atividade sexual pode acelerar o processo de envelhecimento fisiológico e psicológico, pois o abandono de uma atividade pode resultar em alteração de outras funções. A regularidade constante da atividade sexual acompanhada de orientação profissional adequada pode contribuir com o aumento do bem-estar físico, social e psicológico.

Compreende-se, então, que a sexualidade não é uma necessidade inútil, absurda, um luxo ou acessório, mas importante, pois contribui para a manutenção de uma boa saúde da pessoa idosa. É fundamental que os idosos possam falar com liberdade sobre os seus problemas sexuais com os profissionais que os assistem e com suas famílias.

Para que o Brasil atinja o ideal do envelhecimento ativo/bemsucedido, as tecnociências precisam romper com a posição dominante assumida pelo ideário neoliberal e posicionarem-se democraticamente através da conjugação de saberes entre profissionais e idosos e familiares e idosos (intergeracionalidade) na construção de um novo senso comum que se paute no ser humano em detrimento às práticas que entronizam o consumo e os padrões estéticos socialmente estabelecidos.

\section{REFERÊNCIAS}

ALBUQUERQUE, Sandra Márcia Lins de. Envelhecimento ativo: desafio do século. São Paulo: Andreoli, 2008; 
ALMEIDA, Vera Lúcia Valsecchi. Modernidade e Velhice. In: Revista Serviço Social \& Sociedade. Ano XXIV , n 75 - setembro 2003;

BEAUVOIR, Simone de. A velhice. Editora: Nova Fronteira, 1990;

BRASIL. Organização Mundial da Saúde. Disponível em: www.paho.org/bra;

BRASIL. Pesquisa Nacional por Amostras de Domicílios (PNAD), 2012. Disponível em: www.ibge.gov.br;

BRUNO, Fernanda. O biopoder nos meios de comunicação: o anúncio de corpos virtuais. Revista Comunicação, mídia e consumo. São Paulo: Volume 3, Número 6, Página 63-79, Março de 2006;

CAPODIECI, Salvatore. A idade dos sentimentos: amor e sexualidade após os sessenta anos. Tradução de Antonio Angonese. Bauru, SP: EDUSC, 2000;

CERQUEIRA, Monique Borba. Digressões sobre saúde, envelhecimento e vida saudável na contemporaneidade. Dossiê - $\mathrm{O}$ final do século XXI, v 17, n 2, p 26, 2012;

DEBERT, Guita; BRIGEIRO, Mauro. Fronteiras de gênero e sexualidade na velhice. Revista Brasileira de Ciências Sociais, vol. 27, Número 80, p. 37-54, São Paulo: Outubro de 2012;

FENSTERSEIFER, Paulo Evaldo. O imperativo do idoso saudável: dimensões éticas. In: Envelhecimento humano: campo de saberes e práticas em saúde coletiva. Loiva Beatriz Dallepiane (org.). Ijuí, Editora Unijuí, 2009 (Coleção Saúde Coletiva);

FERNANDES, Maria das Graças Melo. Problematizando o corpo e a sexualidade de mulheres idosas: o olhar de gênero e a geração. Revista enfermagem. UERJ, Rio de Janeiro, 2009. Jul./Set.;

GONÇALVES, Sandra. Corpo e Salvação contemporânea. Revista Verso e Reverso - Revista da Comunicação. ISSN 1806-6925; Volume 23, Número 53, Ano 2009;

GUSMÃO, Neusa Maria M. Infância e velhice: pesquisa de ideias. Campinas: Átomo \& Alínea, 2003;

ISTO É, Revista. Quanto mais velho, melhor: O Mercado cresce para quem se especializa em cuidar de idosos. Sessão: Saúde. 27 jan./2010. Ano $34, n^{\circ} 2098$ 
LITVOC, Júlio e BRITO, Francisco Carlos. Conceitos Básicos. In: Envelhecimento - Promoção e Prevenção da Saúde. Júlio Litvoc e Francisco Carlos Brito (orgs.). São Paulo. Editora Atheneu, 2004;

MERCADANTE, Elisabeth F. Velhice: a identidade estigmatizada. In: Revista Serviço Social \& Sociedade. Ano XXIV , n 75 - setembro 2003;

NERI, Anita Liberalesso (org.). Desenvolvimento e Envelhecimento Perspectivas biológicas, psicológicas e sociológicas. $2^{\circ}$ ed. Campinas, SP: Papirus, 2001 (Coleção Vivaidade);

NETTO, Matheus Papaléo; PONTE, José Ribeiro da. Envelhecimento: desafio na transição do século. In: Gerontologia: a velhice e o envelhecimento em visão globalizada. Matheus Papaléo Netto (org.). São Paulo. Editora Atheneu, 2005;

PASCUAL, Cosme Puerto. A sexualidade do idoso vista com novo olhar. Edições Loyola, São Paulo, Brasil, 2002;

PEIXOTO, Clarice. Entre o estigma e a compaixão e os termos classificatórios: velho, velhote, idoso, terceira idade. In: Velhice ou Terceira Idade. Fundação Getúlio Vargas, Rio de Janeiro, 1998;

ROCHA, Gilmar. Sob o signo de saturno: reflexões antropológicas em torno da velhice. Cad. serv. Soc., Belo Horizonte, v. 3, n. 3, p. 26-55, dez., 1998;

SCHUBERT R, Nuremberg. Tarefas e metas da gerontologia. In: GADAMER H.-G; VOGLER P. (Org.) Nova Antropologia: o homem em sua existência biológica, social e cultural; São Paulo, EDUSP, 1977.

TEIXEIRA, Solange Maria. Envelhecimento e trabalho no tempo do capital - Implicações para a proteção social no Brasil. São Paulo, Cortez: 2008;

UBESSI, Liamara Denise et al. A sexualidade vivenciada por idosos residentes em instituição de longa permanência sob a perspectiva da promoção da saúde. In: Envelhecimento humano: campo de saberes e práticas em saúde coletiva. Loiva Beatriz Dallepiane (org.). Ijuí, Editora Unijuí, 2009 (Coleção Saúde Coletiva);

YANARICO, Agustín Apaza. Uma tecnociência para o bem-estar social. Revista do observatório do movimento pela tecnologia social da América Latina Ciência \& Tecnologia Social - a construção crítica da tecnologia pelos atores sociais. Volume 1, Número 1, Julho de 2011. 